\title{
Hume Reads Freud: Empiricism as Rhetorical Event
}

\section{ABSTRACT}

The two competitive currents in French philosophy initiated by Jacques Derrida and Gilles Deleuze tackle the difference between empiricism and idealism in contrary motion. In Derrida, the move is toward a critique of representation. In Deleuze, it is toward recovery of the real. Nevertheless, this paper nominates their meeting in a kind of 'radical empiricism'. Both Derrida and Deleuze engage with empiricism at certain points in their work, although many who go by that label would be surprised to hear it.

KEYWORDS: Derrida, Deleuze, Hume, Freud, empiricism

The difference between empiricism and idealism is not intelligible, within the rationality that either supposedly supports. On the one hand, it is reductive to suppose one meets in observation with a 'real', which is selfdisclosing and unmediated. On the other, to propose that reality is subordinated to an $a$ priori of reason, which represents it, is unduly to fuse together the laminate of thought and the real. 
The two competitive currents in French philosophy initiated by Jacques Derrida and Gilles Deleuze tackle this difference in contrary motion. In Derrida, the move is toward a critique of representation. In Deleuze, it is toward recovery of the real. Nevertheless, this paper nominates their meeting in a kind of 'radical empiricism'. Both Derrida and Deleuze engage with empiricism at certain points in their work, although many others who go by that label would be surprised to hear it.

The sense in which the two can be said to be responsive to the aspirations of a certain empiricism is related to the sense in which they also display affinities with psychoanalysis. In what follows, I sketch a consonance in their work by tracing a filiality in their readings of Hume and Freud respectively, cast as empiricist philosophers of mind.

I look at how the philosophical problems produced by, and as, empiricism can be seen as surprisingly important to the philosophical diagnostics undertaken by both, especially when seen in the light of this Freudian colour. The critiques of institutional psychoanalysis offered by Derrida and Deleuze are to be understood as correctives to the orthodox psychoanalytic readings, which close down the ontological openness in Freudian concepts. But it is in their philosophical habits, as much as in their propositions, that intuitions of the relation of thought to the real are explored.

Derrida and Deleuze share this: conceptuality is understood always in conjunction with its means of representation. This gives a Freudian colour to their empiricism, in terms of the possibility of a rhetoric of thought as presented in, among other texts, The Interpretation of Dreams.

\section{I}

Deleuze's Hume places the nature of thought within the experience by which it is known, thinking. For example, he reflects on Hume's observation of repetition, that it 'changes nothing in the object repeated, but does change something in the mind which contemplates it....' Deleuze asks:

Does not the paradox of repetition lie in the fact that one can speak of repetition only by virtue of the change or difference that it introduces into the mind which contemplates it? By virtue of a difference that the mind draws from repetition? ${ }^{1}$ 
This intuition, of a difference the mind itself draws from the experience of repetition, inaugurates, in Deleuze's reading of Hume, the principles of association, which will form the subject as a thinking subject. In the introduction to Empiricism and Subjectivity, Deleuze remarks of a conventional reading of Hume that;

The point of view of the origin, according which every idea derives from a pre-existing impression and represents it, does not have the importance that people attribute to it: it merely gives the mind a simple origin and frees the ideas from the obligation of having to represent things ... The essence and destiny of empiricism are not tied to the atom but rather to the essence of associations; therefore, empiricism does not raise the problem of the origin of the mind but rather the problem of the constitution of the subject. ${ }^{2}$

It is empiricist of Hume to insist, not on the veracity of an apparent world gleaned through the senses, but on a forming of the operations of thought as a matter of practice in every case. That is, experience lies outside and as a precondition to reason; the rational does not dictate to thought, rather the mind's affections are the material from which its rationality and consciousness are fashioned.

This makes Hume's philosophy "a sharp critique of representation," and "subjectivity is determined as an effect" Deleuze writes. ${ }^{3}$ Hume is a critique of later philosophy in which

rationalism has transferred mental determinations to external objects, taking away thereby from philosophy the meaning and intelligibility of practice and the subject. The fact is, though, that the mind is not reason; "reason is an affection of the mind"; [and even] "Reason is a kind of feeling." ${ }^{4}$

It may be evident from this that Deleuze's Hume is a different text from the British analytic one - Hume reads Freud. ${ }^{5}$ Hume's empiricism is not found in his insistence on the origin of the mind's objects in the external world, but on the construction of the mind from principles experienced outside the rational. Characterising the strength of Hume's philosophy of mind, Deleuze reflects on the options, which various writers have chosen in order to determine the nature of the mind:

Sometimes, these factors are the body and matter, in which case psychology makes room for physiology. Sometimes they are particular principles 
constituting a psychic equivalent of matter, wherein psychology finds its unique, possible object and its scientific condition. Hume, with his principles of association, has chosen the latter route, which is the most difficult and the most audacious. This is where his sympathy for materialism comes from, and at the same time his reticence toward it. ${ }^{6}$

A sympathy for materialism, since it allows for the impressions of experience to be infinitely varied according to practice and without being confined in advanced to any particular law; yet a reticence, since this mental material is also always formed in some sense. Formation is the question that the principles of association are designed to answer. As Deleuze remarks elsewhere, for Hume, the important question is how the collection of impressions becomes a system. ${ }^{7}$

One can observe a similarity here with Freud, whose 'metapsychology' is designed to give an account of the mind in psychological, and not physical, terms; we can compare this observation of Deleuze's with Freud's own account of his methodology in Beyond the Pleasure Principle.

To meet a suspicion that the story of the death drive is a little far-fetched, Freud reassures us:

This is merely due to our being obliged to operate with the scientific terms, that is to say, with the figurative language, peculiar to psychology ... We could not otherwise describe the processes in question at all, and indeed we could not have become aware of them. ${ }^{8}$

This remarkable comment hints at a radically different view of the relationship between scientific writing and observation than the positivist one with which he is often credited. Here Freud not only recognises that the observation relies on a pre-existing lexicon to 'describe the processes in question' this lexicon being the notable innovation of psychoanalysis. But more, it is only through the fabrication of the theoretical terms of the science that these observations themselves become apparent. It is as though having invented the terms sharpens observation and allows for their discernment. ${ }^{9}$

Freud then refers to the hope he cherished, from the Project for a Scientific Psychology, for a 'hard science' account of nervous illness. This hope is still very much alive, as cognitive science today grapples with whether electrochemical descriptions of brain states would add anything to consciousness of them. 
The deficiencies in our description would probably vanish if we were already in a position to replace the psychological terms by physiological or chemical ones. It is true that they, too, are only part of a figurative language; but it is one with which we have long been familiar and which is perhaps a simpler one as well. ${ }^{10}$

Elsewhere, Freud has addressed the criticism of the indirectness of psychoanalytic observations - that these processes of repression and instinctual vicissitudes and so on, are known only through symptoms and by report. This has been a difficulty for psychoanalysis and its claims to scientific status from early on. Freud answers it in the New Introductory Lectures, for example, by drawing attention to other sciences whose evidence is similarly indirect - astronomy, geology, and so on. ${ }^{11}$ We might add to this the contemporary observations of particle physics and molecular biology, whose protocols of observation are highly mediated and artificial. The further obstacle to psychoanalytic observation in terms of the empirical is not only the text but the context of its observing. The analytic setting is much more like fieldwork than the laboratory. But even here, the complexity of variation of factors might be compared with a science such as meteorology, for which models are routinely devised to schematise context.

The residual element, which is unresolved, is the perception that analysis is also a field of action and interaction. Far from being deterred at this difference, Freud instead develops the theoretical vocabulary to address this dynamic as a scientific object; he calls it the 'transference'. Psychoanalysis is revealed, not as anomalous, but as paradigmatic, as the effect of the observer on the observation becomes critical to the definition of other scientific processes.

These other scientific languages, then, are not 'truer' in Freud's view — 'they are themselves figurative'. They have different virtues; they are familiar and simpler than the scientific neologisms of psychoanalysis. These preferences are those of the rhetorician as much as the scientist.

In Freud, one finds the minute and insistent attention to ambivalence and plurivocity of expression. The very idea of the unconscious implies this; in The Interpretation of Dreams, Freud draws attention to the necessity of thoughts to present themselves in the form/format appropriate to the genre. The dream is conditioned by its means of representation, and he details many of the 
'rhetorical devices' that the dream as a pictorial text must employ to represent logical and other non-visual relations. ${ }^{12}$

This sensitivity to genre is present throughout Freud's work, for the analysis is always of an expression which is subject to competing needs of representation - repression, desire, and so on - and the 'genre' is always a matter of circumstantial fact. The symptom, for example, might be hysterical or it might be obsessive-compulsive; these are texts belonging to separate genres, and the resulting 'representation' looks very different in each — one is paralysed, the other cannot resist repeating a gesture - and yet reading their terms and logical relations according to psychoanalysis, they may yield analogous ideas.

This connection between the idea and its expression also raises the problem of empiricism. It is not that analysis is 'mere interpretation', just as philosophy cannot be 'truth itself' - only the naive realist imagines that, through empirical means, things are 'represented as they really are'. The work of the dream is conditioned by condensation and displacement of the dream-thoughts underlying it, but there is also "a third factor whose share in the transformation of the dream-thoughts into the dream-content is not to be underrated: namely, considerations of representability in the peculiar psychical material of which dreams make use ..."13

The psychical material in question is an assortment of wishful unconscious thoughts - Freud's dream text is 'peculiar' in the sense that it is read as formed by forces, some of them generic, rather than as expressive of meanings. But in time, this peculiarity comes to infect all thought and thinking, so that Freud will sketch 'the psychopathology of everyday life', for example, as also expressive of manifold desires in multiple genres of speech, gesture and action.

In the transference, this peculiarity of the force in formation of thought expands to characterise completely the interactions between a person and their analyst, and indeed reaches its widest ambit in the 'fate neurosis' Freud speaks of, where the whole course of a relationship is given by the repetition of unconscious desire. The transference, as a living text, captures the expressivity of thought as a kind of experience.

If Freud makes of thought a text, then, he makes of rhetoric a desire, which is to say a force. His thinking on the nature of the psyche brings together the 
questions of thought and the real; what it is, in terms of how it is to be represented.

An empiricism that Freud and Hume seem to share allows for the contradiction that is the subject; that it is a circumstantial collection of the given, but that it is also the transcendence of the given, in that which makes of the collection something systematic. The principles of association are necessarily transcendent, and cannot represent experience of ideas. They represent experience of the relations perceived between ideas, which nevertheless occur as a kind of experience in the subject.

This subject who invents and believes is constituted inside the given in such a way that it makes the given itself a synthesis and a system. This is what we must explain. In this formulation of the problem, we discover the absolute essence of empiricism. ${ }^{14}$

How are we to understand the empirical, on this view? Deleuze asks:

But what is the given? It is, says Hume, the flux of the sensible, a collection of impressions and images, or a set of perceptions ... Empiricism begins from the experience of a collection, or from an animated succession of distinct perceptions. ${ }^{15}$

Deleuze, extending his earlier correction of misreadings of Hume, distils empiricism as fundamentally the principle of difference: "not that 'every idea derives from an impression' ... but rather that 'everything separable is distinguishable and everything distinguishable is different"." [And] "we must begin with this experience because it is the experience."16

The empirical is the encounter between thought and the real. It is never free of the subject, but on the contrary is the only expression possible of the subject, and is its best expression, too. This empiricism is also a materialism because it amounts to specifying that ideas are substance - in as much as the term has utility - since perceptions are the substances of which we have experience. Matter is not outside the mental, nor is there a noumenal world of greater substance than our thought. Empiricism dispenses with this nostalgia, which is really a gesture toward a difference that lies on the other side of the concept of distinction. 
Ideas then are given in their difference, and the subject constitutes itself in the given, by virtue of principles which are given in another way, as tendencies of the collection itself to associate between separable moments. Relations, for empiricism, are external to ideas. "When James calls himself a pluralist, he does not say, in principle, anything else. This is also the case when Russell calls himself a realist. We see in this statement the point common to all empiricisms." 17

But if the relations must come from outside the particular ideas they associate, then there can only ever be a circumstantial explanation of any relation; it will never be necessary. "[A] true judgement is not a tautology."18 Expression is conditioned by exigency, and observation, too, is circumstantial. This is what Deleuze believes Hume and Freud have in common:

If it is true that association is necessary in order to make all relations in general possible, each particular relation is not in the least explained by the association. Circumstance gives the relation its sufficient reason ... [And] when Freud and Bergson demonstrate that the association of ideas explains only that which is superficial in us, that is, only the formalism of consciousness, they mean, essentially, that only affectivity can justify the singular content, the profound and the particular. And they are right. But Hume has never said anything else. ${ }^{19}$

\section{II}

Deleuze and Guattari are critical of a certain psychoanalysis, one full of ideas whose itineraries are fixed: "In its idealism, its domestic and theatrical idealism, it completely misses the unconscious character of sexuality." ${ }^{20}$ This is quite a charge to lay at the door of a practice to which Freud entrusted the task of recognising the action of the unconscious and sexuality in psychical life. Psychoanalysis takes upon itself the responsibility of diagnosing the beyond and behind of thinking, thinking in its material and milieu, the medical problem of toxic thoughts. ${ }^{21}$

This 'idealism' is "a whole system of projections, of reductions, in analytic theory and practice... The Oedipus complex is basically an apparatus for repressing desiring machines, and is in no sense a formation of the unconscious itself." 22 The Oedipus complex appears to schizoanalysis as itself a form of secondary revision, in a theory that acts unconsciously. ${ }^{23}$ 
Derrida, too, is quick to declare a resistance to psychoanalysis in its institutional settings. ${ }^{24}$ At the same time, in an epilogue to his early paper "Freud and the Scene of Writing," Derrida considers the influence of psychoanalysis on deconstruction, and calls for the Freudian concept of the trace to be 'radicalised and extracted' from the metaphysics of presence, since it is the trace which makes possible the concept of an unconscious..$^{25}$

This radicalisation of the thought of the trace would open up the chances of a thought 'fecundated by psychoanalysis', and Derrida enumerates some possibilities in that epilogue. However, it is clear that an obstacle is still in the way of such reflections, one that is central to the discussion in this paper; that is, the insistence of a certain kind of empiricism on the 'real' contact thought may have with the real. This dogmatics weighs down the social sciences, and contributes to the gratitude that is sometimes felt toward Derrida and Deleuze (not forgetting Foucault) in their surprising analyses of different scenes of knowledge. At issue is an ontological commitment that underlies a certain empiricism and Freudianism and which, in Derrida and Deleuze's work, is contrasted with a foundationalism that both, in their different ways, reject.

The main body of Derrida's argument in "Freud and the Scene of Writing" dwells on two uses of the writing metaphor in Freud that capture Derrida's imagination - of the mental as a kind of writing, and of the memory as a trace. Both these concepts, as he points out, threaten at the same time as they aspire to the logic of presence: "In what ways would the Freudian concepts of writing and trace still be threatened by metaphysics and positivism?"26 The labour of the argument is to unveil, nevertheless, "all the differences which furrow Freudian conceptuality," and which bring presentation, writing, trace, repression, pleasure, reality, consciousness, death drive, even psyche, to the brink of the non-concept, in the vicinity of différance. ${ }^{27}$

The main argument concludes that through Freud's rhetorical procedure, something is 'spoken without being said, that is, is represented.' Importantly, it is the concept of writing that is mobilised here to that effect. "[S]tarting with the Traumdeteung (1900), the metaphor of writing will appropriate simultaneously the problems of the psychic apparatus in its structure and that of the psychic text in its fabric." ${ }^{28}$ 
Freud brings into the ambit of a scientific psychology the modern problematic which will develop into 'structuralism' in the following century - we need to give to Freud that originality at the same time as that myopia, as Derrida notes when he reflects on the immense labour of deconstruction that is required in regarding "the metaphysical complications of psychoanalysis and the socalled human (or social) sciences (the concepts of presence, perception, reality, etc.)." ${ }^{29}$ In so doing, Freud thoroughly contaminates the question of thought with the question of representation, such that positivism cannot succeed. Derrida witnesses "the precautions and nominalism with which Freud manipulates what he calls conventions and conceptual hypotheses." ${ }^{30}$

These moments are critically linked to Freud's understanding of his own method, even granted Derrida's criticism that Freud "never reflected upon the historical and theoretical sense of these precautions. ${ }^{\prime \prime 1}$ Freud habitually avoids such reflection by an appeal to the empirical basis of his observation. In many places, especially where what is hypothesised seems fantastic, Freud defends himself with reflections on how the concepts of psychoanalysis are derived from the observations made in analysis. In other places, Freud dismisses philosophy as an activity he is both ignorant of and unsuited to - in particular, so as to underline his native virtue of observation. ${ }^{32}$

The claim to the immaculate in observation, and the observation of the aporetic in Freud's writing, are not antithetical, but on the contrary are fundamental to the Freudian influence. The rhetorical event that characterises the aporetic for Derrida is outlined as "repression, not forgetting; repression, not exclusion. Repression, as Freud says, neither repels, nor flees, nor excludes an exterior force; it contains an interior representation laying out within itself a space of repression." ${ }^{33}$

And the epiphany of the argument:

In that moment of world history 'subsumed' by the name of Freud, by means of an unbelievable mythology (be it neurological or metapsychological...), a relationship to itself of the historico-transcendental stage of writing was spoken without being said, thought without being thought; was written and simultaneously erased, metaphorised ... it was represented. ${ }^{34}$

This repression/representation is the scene of writing itself. Freud understands the relation of thought to the real, he understands it as the problem 
in what terms it is to be represented. This haunted question, of how one is to describe what one sees, will escalate and become the whole scene, in the century of social science to come.

"And like all who know how to write, he [Freud] let the scene duplicate, repeat, and betray itself within the scene." ${ }^{\prime 35}$ The Interpretation of Dreams can be read as an extended explication of the rhetoric of this scene. Derrida finds it a virtue in Freud that repression emerges as an'interior presentation', not only within the concept but within the writing of it. Repression characterises the unconscious, the conserving of a possibility contrary to the conscious or the explicit. It is because Freud's concepts of repression and unconscious do not destroy, but instead harbour ideas unacceptable to consciousness, that Freud is pluralist in the sense Derrida admires. The tolerance of plurivocity is important, but more important still is the power of the figure to harbour ambivalence and thereby not to succumb to the dogmatism of truth. Freudian texts do not merely allow difference to present itself, but insist on the difference by presenting also the force of its contradiction. (Deleuze has seen the same virtue in Hume's philosophy of mind.)

Derrida often works with models that imagine this harbouring, as part of his analysis of the structures of aporia in thought, including Freud's own. Writing is both a subject of analysis for Derrida - especially the writing of philosophy - and is also an example of a particular configuration that Derrida addresses throughout the problems he tackles. This configuration has the structure of aporia; that is, it represents a sort of impossibility. The aporetic Derrida aptly describes as an experience.

What if the exoteric aporia therefore remained in a certain way irreducible, calling for an endurance, or shall we rather say an experience other than that consisting in opposing, from both sides of an indivisible line, an other concept... ${ }^{36}$

To counter the criticism of deconstruction that it is essentially negative, and offers nothing to the problems it analyses, Derrida seeks to bring into focus the affirming possibilities of the aporia, without turning to a mysticism that reverts to a theological style of thought. ${ }^{37}$ Freud's concepts of repression, the unconscious and repetition, are all capable of such an affirmative, since they describe the productive place of the sign in mental life. This aspect of Freud 
is perhaps brought out most explicitly in the structuralist readings of Freud made by Jacques Lacan. But Freud interests Derrida more, because the struggle that empirical science has with signification is still active in his theorising. Lacan's discourse artfully engages the question of science as though there had already been a battle between structuralism and empiricism, and structuralism had won.

Derrida, considering structuralism to have its own problems with origin and presence, prefers an aspiring empiricism confronted with the evidence of its shortcomings. Lacan's rhetorical style has taken him beyond the social sciences, but Freud remains pivotal in them; those discourses which attempt to give an account of the real as observed, with greater or less sensitivity to this impossibility.

Lévi-Strauss is Derrida's example, in the paper "Structure, Sign and Play in the Discourse of the Human Sciences." Lévi-Strauss is a structuralist, but one who considers himself still to be constrained by an empirical element. In discussing his work, Derrida focuses on the social sciences and its awkward role as discourse and interpretation of the real world. And the concepts of psychoanalysis play their part in Lévi-Strauss's aspirations to understand myth, kinship and other elements of culture. ${ }^{38}$

Derrida admires Lévi-Strauss for his grasp of writing, specifically an ethnography that takes on the risk of its repression, in the form of the bricolage. The 'mythopoetical virtue of bricolage' is that it abandons pretensions to a centre as a 'critical search for a new status of discourse'. "In opposition to 'epistemic' discourse, structural discourse on myths — 'mythological' discourse - must itself be 'mythomorphic'. It must have the form of that of which it speaks." ${ }^{\prime 39}$

The absence of any real and fixed centre of the myth - author or origin demands this methodology of the bricoleur:

it is at this point that ethnographic bricolage deliberately assumes its mythopoetic function. But by the same token, this function makes the philosophical or epistemological requirement of a centre appear as mythological, that is to say, as a historical illusion. ${ }^{40}$

However, in abandoning the centre, the problem of the loss of a magnetic pole in judgement is now raised: "Shall we have to abandon any epistemo- 
logical requirement which permits us to distinguish between several qualities of discourse on myth?"41 This question cannot be answered properly, Derrida tells us, until the rhetorical difference between theory and myth is posed explicitly as a philosophical problem. Significantly, until it is so posed, the discourse will seem only as though it is faulty philosophy.

I have said that empiricism is the matrix of all faults menacing a discourse which continues, as with Lévi-Strauss in particular, to consider itself scientific. If we wanted to pose the problem of empiricism and bricolage in depth, we would probably end up very quickly with a number of absolutely contradictory propositions concerning the status of discourse in structural ethnology. On the one hand, structuralism justifiably claims to be the critique of empiricism. But at the same time there is not a single book or study by Levi-Strauss which is not proposed as an empirical essay which can always be completed or invalidated by new information. ${ }^{42}$

Derrida finds that theoretical writing, and particularly, the social sciences as the form of theoretical writing most intensely caught in this contradiction, cannot reconcile the tension between these two views of signification:

The one seeks to decipher, dreams of deciphering a truth or an origin which escapes play and the order of the sign, and which lives the necessity of interpretation as an exile. The other, which is no longer turned toward the origin, affirms play and tries to pass beyond man and humanism ... ${ }^{43}$

These are "absolutely irreconcilable even if we live them simultaneously and reconcile them in an obscure economy," and it is in the oscillation of this ambivalence that a knowing science must find its 'empirical'. ${ }^{44}$ But to pose the problem of the difference between theory and myth philosophically, will require an understanding not just of writing, but also of the rationality to which theory is pinned.

\section{Conclusion}

The work of Derrida and Deleuze shows in different ways that it is empiricism that raises the demanding question of signification: what are the terms of my observation?

An empiricism to which both Hume and Freud can be read as acceding requires that, if it is possible to describe the representation of thought, and 
to detail the constitution of the subject, it is nevertheless impossible to specify it in advance of the encounters that make thought of experience, and thus constitute its subject. And experiencing the given will always exceed the forms given to it - differences are infinitely varied and arise in the wake of its expression, as well as in the penumbra of circumstances which gave rise to it. As Deleuze explores it:

Empiricism is by no means a reaction against concepts, not a simple appeal to lived experience. On the contrary, it undertakes the most insane creation of concepts ever seen or heard. Empiricism is a mysticism and a mathematicism of concepts, but precisely one which treats the concept as object of an encounter, as a here-and-now, or rather as an Erewhon from which emerge inexhaustibly ever new, differently distributed 'heres' and 'nows'. Only an empiricist could say: concepts are indeed things, but things in their free and wild state, beyond anthropological predicates. ${ }^{45}$

In its vulgar variety as the simple revealing of reality - the 'scientific facts' with which we are bombarded - empiricism is caught in an aporia which guarantees the reproduction of certain vital and unconscious myths. And in its more enigmatic version, as a philosophy of differences, the question is answered only circumstantially, as a theoretical event that knows no guarantee.

Structuralism is said to have the better of the question of signification, since it recognises the role of difference in the interpretability of any structure of signs. This is the sense that Derrida alludes to when he says structuralism is 'justifiably' held to be the critique of empiricism. But on Deleuze's reading, empiricism lets in the real difference; that is, the new, shocking and illegible differences lying outside the comprehensibility of the structure constituted by differences appearing in their Hegelian negativity. The transcendental, which is the problem of subjectivity on Deleuze's reading of Hume, remains a paradox, just as the empirical, following Derrida's reading of Lévi-Strauss, becomes an aporia.

There can be a lyric sense of the empirical, all the same. Writes Derrida, "... the joyous affirmation of the play of the world and of the innocence of becoming, the affirmation of a world of signs without fault, without truth, and without origin which is offered to an active interpretation." ${ }^{46}$ Writes Deleuze, "I make, remake and unmake my concepts along a moving hori- 
zon, from an always decentred centre, from an always displaced periphery which repeats and differentiates them." ${ }^{47}$

It is towards this empiricism as a rhetorical event that Deleuze and Derrida, differently, and with reticence or even trepidation, might all the same be seen to urge us.

* Associate Professor Robyn Ferrell, School of Philosophy, University of Tasmania, Private Bag 41, Hobart, Tasmania, Australia, 7001

\section{Notes}

1 Gilles Delueze, Difference and Repetition, trans., Paul Patton, New York, Columbia University Press, 1994, p. 70.

2 Gilles Deleuze, Empiricism and Subjectivity, trans., Constantin Boundas, New York, Columbia University Press, 1991, p. 31.

3 Deleuze, Empiricism and Subjectivity, p. 30; p. 26.

$4 \quad$ Ibid., p. 30.

5 Robyn Ferrell, "Rival Reading: Deleuze on Hume," Australasian Journal of Philosophy, vol. 73, no. 4, December, 1995, pp. 585-593.

6 Deleuze, Empricism and Subjectivity, p. 28.

7 Ibid., p. 22.

8 Sigmund Freud, Beyond the Pleasure Pleasure, Standard Edition, London, Hogarth, vol. 18, 1920, p. 60 (my emphasis).

9 Cf. Robyn Ferrell, Passion in Theory, Routledge, London, 1996, p. 56.

10 Freud, Beyond the Pleasure Principle, (my emphasis).

11 Sigmund Freud, New Introductory Lectures on Psychoanalysis, Standard Edition, vol. 22, London, Hogarth, 1933, p. 32.

12 Sigmund Freud, The Interpretation of Dreams, Standard Edition, Vols. 4 and 5, 1900, chapter 6 .

$13 \quad$ Ibid., pp. 343-344.

14 Deleuze, Empiricism and Subjectivity, p. 87.

15 Ibid.

16 Ibid., p. 88.

17 Ibid.

$18 \quad$ Ibid., p. 98.

19 Ibid., p. 103.

20 Gilles Deleuze, Essays Critical and Clinical, trans., Daniel W. Smith, Minneapolis, University of Minnesota Press, 1997, p. 18.

21 Robyn Ferrell, Genres of Philosophy, Aldershot, Ashgate, 2002, p. 122. 
Deleuze, Essays Critical and Clinical, p. 17.

Cf. Deleuze and Guattari, Anti-Oedipus: Capitalism and Schizophrenia, trans., Hurley et al., Minneapolis, University of Minnesota Press, 1983.

24 Jacques Derrida, Resistances of Psychoanalysis, trans., Peggy Kamuf et al., Stanford, Stanford University Press, 1998; The Postcard: From Socrates to Freud and Beyond, trans., Alan Bass, Chicago, Chicago University Press, 1987.

25 Jacques Derrida, Writing and Difference, trans., Alan Bass, London, Routledge \& Kegan Paul, 1978, p. 196.

$26 \quad$ Ibid., p. 198.

27 Ibid.

$28 \quad$ Ibid., p. 206.

$29 \quad$ Ibid., p. 198.

30 Ibid.

31 Ibid.

32 Cf. Derrida, The Postcard: From Socrates to Freud and Beyond, trans., Alan Bass, Chicago, University of Chicago Press, 1987, pp. 263-5.

33 Derrida, Writing and Difference, p. 196.

34 Ibid., pp. 228-229.

35 Ibid., p. 229.

36 Derrida, Aporias, trans., Thomas Dutoit, Stanford, Stanford University Press, 1994, pp. 14-15.

37 Paul Patton, Deconstruction Engaged, Sydney, Power Institute, 2002.

38 Derrida, Writing and Difference, p. 278.

$39 \quad$ Ibid., p. 286.

$40 \quad$ Ibid., p. 287.

41 Ibid.

$42 \quad$ Ibid., p. 288.

$43 \quad$ Ibid., p. 292.

$44 \quad$ Ibid., p. 293.

45 Deleuze, Difference and Repetition, pp. xx-xi.

46 Derrida, Writing and Difference, p. 292.

47 Deleuze, Difference and Repetition, pp. xx-xi. 


\section{University Library}

\section{- M M I N E R VA A gateway to Melbourne's research publications}

Minerva Access is the Institutional Repository of The University of Melbourne

Author/s:

FERRELL, ROBYN

Title:

Hume reads Freud: empiricism as rhetorical event

Date:

2003

Citation:

Ferrell, R. (2003). Hume reads Freud: empiricism as rhetorical event. Critical Horizons, 4(2), 265-280.

Publication Status:

Published

Persistent Link:

http://hdl.handle.net/11343/34098 